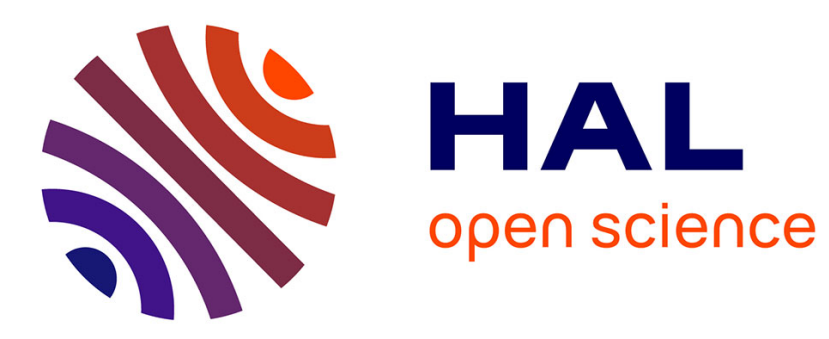

\title{
NMR investigations of polytrifluoroethylene (PTrFE) synthesized by RAFT
}

Vincent Bouad, Marc Guerre, Sami Zeliouche, Bruno Ameduri, Cédric Totée, Gilles Silly, Rinaldo Poli, Vincent Ladmiral

\section{- To cite this version:}

Vincent Bouad, Marc Guerre, Sami Zeliouche, Bruno Ameduri, Cédric Totée, et al.. NMR investigations of polytrifluoroethylene (PTrFE) synthesized by RAFT. Polymer Chemistry, 2021, 12 (15), pp.2293-2304. 10.1039/D0PY01753A . hal-03188630

\section{HAL Id: hal-03188630 \\ https://hal.science/hal-03188630}

Submitted on 9 Apr 2021

HAL is a multi-disciplinary open access archive for the deposit and dissemination of scientific research documents, whether they are published or not. The documents may come from teaching and research institutions in France or abroad, or from public or private research centers.
L'archive ouverte pluridisciplinaire HAL, est destinée au dépôt et à la diffusion de documents scientifiques de niveau recherche, publiés ou non, émanant des établissements d'enseignement et de recherche français ou étrangers, des laboratoires publics ou privés. 


\title{
NMR investigations of Polytrifluoroethylene (PTrFE) made by RAFT
}

Received 00th January 20xx, Accepted 00th January 20xx

DOI: $10.1039 / x 0 x \times 00000 x$

\author{
Vincent Bouad ${ }^{a}$, Marc Guerre ${ }^{b}$, Sami Zeliouche ${ }^{a}$, Bruno Améduria ${ }^{a}$ Cédric Totée $^{a}$, Gilles Sillya ${ }^{\text {, Rinaldo }}$ \\ Polic, Vincent Ladmirala*
}

Trifluoroethylene (TrFE) is a relatively rare fluorinated monomer mainly used in copolymerisation with vinylidene fluoride (VDF) to prepare ferroelectric materials. While the VDF homopolymerisation has been relatively well studied, that of TrFE is still poorly understood and the reversible deactivation radical polymerisation of this monomer has never been studied in depth. To better understand the RAFT polymerisation of TrFE, the accurate assignments of PTrFE made by RAFT polymerisation is necessary. Thus, this article reports detailed ${ }^{19} \mathrm{~F},{ }^{1} \mathrm{H}$ and ${ }^{13} \mathrm{C} 1 \mathrm{D}$ and $2 \mathrm{D}$ experiments carried out to determine and assign the different NMR chemical shifts and splitting patterns of the $\alpha$ - and $\omega$-chain ends of PTrFE made by RAFT polymerisation.

\section{A. Introduction}

Fluoropolymers constitute an uncommon class of polymers which possess remarkable properties such as a high thermal stability, chemical resistance, good weathering durability, hydrophobic and oleophobic properties as well as electroactivity (ferroelectricity, piezoelectricity...). ${ }^{1,2}$ Within this large family, polyvinylidene fluoride (PVDF) is the second most emblematic fluoropolymers (after polytetrafluoroethylene) and has been studied extensively. ${ }^{3}$ PVDF is especially exploited for its electroactive properties and his monomer is very often copolymerised with TrFE (trifluoroethylene) affording better processability and crystallizing spontaneously in the electroactive phase without the need to stretch process (in comparison to PVDF). While PVDF and P(VDF-co-TrFE) copolymers are relatively common fluoropolymers, PTrFE is rare and much less studied likely due to his cost and poor availability. Therefore, reports detailing PTrFE microstructure and electroactive properties are very scarce. ${ }^{4-6}$ The first study of the microstructure of PTrFE was made by Naylor and Lasoski, ${ }^{7}$ who reported assignments of the $\mathrm{CF}_{2}$ and $\mathrm{CFH}$ NMR resonances of the polymer backbone. The work of Wilson et al. 8 provided the first proof of chain defects in PTrFE. Indeed, TrFE undergoes reverse additions during polymerisation: a radical can attack either onto the monomer tail (the CFH group) or onto the head (the $\mathrm{CF}_{2}$ group). Yagi estimated the amount of backward-added TrFE using Monte Carlo simulations as around $50 \% .{ }^{9}$ It is important to note, however, that Yagi considered backward-added monomers, that is to say monomers inserted via head-to-head $(\mathrm{HH})$ and tail-tohead (TH) additions. This author did not consider tail-to-tail (TT) additions leading to regular (head) propagating radicals. In contrast, all the subsequent studies focussed on chain defects defined as $\mathrm{HH}$ TT addition sequences, probably by analogy with PVDF in which an $\mathrm{HH}$ addition is systematically followed by a TT addition. ${ }^{10}$ Importantly, only Yagi mentioned the possibility of TH additions. Tonelli et al. ${ }^{11}$ made an estimation of the chain defects using ${ }^{13} \mathrm{C}$ NMR. They used the Rotational Isomeric State (RIS) model to predict theoretical spectra and better assign the NMR signals. By integrating the ${ }^{13} \mathrm{C}$ NMR spectrum of PTrFE they estimated the chain defects to represent $50 \%$ of the total number of additions. ${ }^{11}$ Later, they used the same methodology with ${ }^{19} \mathrm{~F}$ NMR spectra and adjusted their theoretical prediction (leading to a new estimation: $11.6 \%$ of chain defects) thanks to the better resolution afforded by ${ }^{19} \mathrm{~F}$ NMR compared to ${ }^{13} \mathrm{C}$ NMR. ${ }^{12}$ Finally, the same authors reported another allegedly more accurate value for this proportion of chain defects (20\%) using ${ }^{1} \mathrm{H}$ decoupled ${ }^{19} \mathrm{~F}$ NMR spectra. ${ }^{13}$ More recently, Harris

\footnotetext{
a. ICGM, University of Montpellier, CNRS, ENSCM, Montpellier, France.

b. Laboratoire des IMRCP, Université de Toulouse, CNRS UMR 5623, Université Paul Sabatier, 118 route de Narbonne, 31062 Toulouse Cedex 9, France.

CNRS, LCC (Laboratoire de Chimie de Coordination), UPS, INPT, université de

Toulouse, 205 route de Narbonne, BP 44099, F-31077 Toulouse, Cedex 4, France.
}

et al. estimated the amount of reverse additions as $13.5 \%$ using the signal assignments reported by Cais et al and better ${ }^{1} \mathrm{H}$ decoupling NMR sequence. ${ }^{14}$

The homopolymerisation of TrFE and the microstructure and properties of PTrFE have been rarely studied. Although TrFE is mentioned as a comonomer in patents dealing with the RAFT polymerisation of fluoromonomers ${ }^{15}$, most PTrFE investigated so far were prepared by conventional radical polymerisation. Reversible deactivation radical polymerisation (RDRP) techniques can help to understand the polymerisation behaviour of fluoromonomers such as VDF or TrFE and to access interesting polymer architectures possessing additional properties. The RAFT polymerisation of VDF has been studied extensively, ${ }^{16,17}$ and a thorough NMR investigation of PVDF made by RAFT gave valuable insights. ${ }^{18}$ Nonetheless, the study of the TrFE RAFT polymerisation is more challenging than that of VDF, due to the presence of the CFH stereogenic center and the higher propensity of TrFE for reverse additions. While a fuller investigation of the TrFE RAFT polymerisation is reported and discussed in another publication, the present article describes in details the NMR investigations carried out to identify the PTrFE microstructure and end-groups produced in the course of the RAFT polymerisation of TrFE.

\section{B. Experimental}

\section{B.1 Materials}

All reagents were used as received unless otherwise stated. Trifluoroethylene (TrFE) was kindly supplied by Arkema (PierreBénite, France). $O$-Ethyl-S-(1-methoxycarbonyl)ethyldithiocarbonate (CTA-XA) was prepared according to the procedure reported by Liu et al. ${ }^{19}$ Tert-amyl peroxy-2-ethylhexanoate (purity 95\%), (Trigonox 121) was purchased from AkzoNobel (Chalons-en-Champagne, France). ReagentPlus grade (purity $>99 \%$ ) dimethyl carbonate (DMC), and tetrahydrofuran (THF) and laboratory reagent grade hexane (purity $>95 \%$ ) were purchased from Sigma-Aldrich and used as received.

\section{B.2 Synthesis}

Two techniques were used to synthesize PTrFE.

Reactor procedure. The synthesis of the PTrFE (entry 4, Table 1) used for the NMR analyses was performed by RAFT polymerisation in a $50 \mathrm{~mL}$ Hastelloy Parr autoclave system (HC 276), equipped with a mechanical Hastelloy stirring system, a rupture disk (3000 PSI), inlet and outlet valves, and a Parr electronic controller to regulate the 
stirring speed and the heating. Prior to reaction, the autoclave was pressurised with 30 bars of nitrogen to check for leaks. The autoclave was then kept under vacuum ( $2010^{-3}$ bar) for 30 minutes to remove any trace of oxygen. A degassed solution of tert-amyl peroxy-2ethylhexanoate, the initiator $\left(0.281 \mathrm{~g}, 1.2210^{-3} \mathrm{~mol}\right)$, and CTA-XA $\left(1.27 \mathrm{~g}, 6.0910^{-3} \mathrm{~mol}\right)$ was introduced via a funnel under vacuum. The reactor was then cooled using a liquid nitrogen bath and $10 \mathrm{~g}$ of TrFE was transferred by double weighing (i.e. mass difference before and after filling the autoclave with TrFE). After warming to ambient temperature, the autoclave was heated to the target temperature under mechanical stirring. The reaction was stopped after $30 \mathrm{~min}$. The autoclave was cooled to room temperature (ca. $20^{\circ} \mathrm{C}$ ), purged the residual monomer, and the dimethylcarbonate was removed under vacuum. The crude product was dissolved in $10 \mathrm{~mL}$ of acetone and left under vigorous stirring for $10 \mathrm{~min}$. This polymer was then precipitated by addition of the acetone solution to $100 \mathrm{~mL}$ of chilled hexane. The precipitated polymer (yellow wax) was filtered through a filter funnel and dried under vacuum (15 $\left.10^{-3} \mathrm{mbar}\right)$ for $2 \mathrm{~h}$ at 40 ${ }^{\circ} \mathrm{C}$. The polymerisation yield ( $2.5 \%$ relative to the monomer) was determined gravimetrically.

Carius tube procedure. The TrFE RAFT polymerisation was carried out in thick $8 \mathrm{~mL}$ Carius tubes in which a solution of the Trigonox ${ }^{\circledast}$ 121 initiator and CTA-XA in DMC $(5 \mathrm{~mL})$ was introduced and then degassed by three freeze-pump-thaw cycles. The gaseous monomer was transferred into the Carius tubes at the liquid nitrogen temperature (TrFE, $1.5 \mathrm{~g}, 1.8310^{-2} \mathrm{~mol}, 0.8 \Delta \mathrm{P}$ ) using a custom-made manifold that enables accurate measurement of quantities of gas (using "pressure drop vs. mass of monomer" calibration curves). The tubes were then sealed under dynamic vacuum at the liquid nitrogen temperature, before being placed horizontally in a shaking thermostatic water bath at $73{ }^{\circ} \mathrm{C}$. The tubes were opened at the desired time and the dimethylcarbonate was removed under vacuum.

The monomer conversions were assumed to be equivalent to the polymer yields, , since conversion is very difficult to measure accurately for TrFE or other gaseous monomers.

\section{B.3 NMR spectroscopy}

The polymer NMR spectra were collected at $25{ }^{\circ} \mathrm{C}$ on a Bruker Avance III 400- $\mathrm{MHz}$ spectrometer equipped with two independent broadband $\left({ }^{15} \mathrm{~N}-{ }^{31} \mathrm{P}\right.$ and $\left.{ }^{15} \mathrm{~N}-{ }^{19} \mathrm{~F}, 300 \mathrm{~W}\right)$ and a high band $\left({ }^{1} \mathrm{H}, 100 \mathrm{~W}\right)$ rf channels. A $5 \mathrm{~mm}{ }^{1} \mathrm{H} /{ }^{19} \mathrm{~F} /{ }^{13} \mathrm{C}$ TXO triple resonance pulsed field gradient probe for which ${ }^{13} \mathrm{C}$ and ${ }^{19} \mathrm{~F}$ are on the inner coil and ${ }^{1} \mathrm{H}$ on the outer coil is used for three channels experiments. This probe has a lower background ${ }^{19} \mathrm{~F}$ signals compared to standard dual-channel probes. This triple resonance ${ }^{1} \mathrm{H} /{ }^{19} \mathrm{~F} /{ }^{13} \mathrm{C}$ probe is capable of producing short $90^{\circ}$ pulses of $6.5 \mu$ s width for ${ }^{19} \mathrm{~F}, 9.5 \mu \mathrm{s}$ for ${ }^{13} \mathrm{C}$ and $9.2 \mu \mathrm{s}$ for ${ }^{1} \mathrm{H}$ channels. In all experiments, ${ }^{1} \mathrm{H}$ decoupling is realized with waltz16. ${ }^{19} \mathrm{~F}$ decoupling was performed with nested loops using $0.5 \mathrm{~ms}$ and $1 \mathrm{~ms}$ chirped adiabatic pulses with $80 \mathrm{kHz}$ bandwidth in order to desynchronize and minimize decoupling artifacts.

$1 \mathrm{H} 1 \mathrm{D}$ NMR. A one pulse $90^{\circ}(9.25 \mu \mathrm{s})$ pulse sequence was used with $6 \mathrm{~s}$ acquisition time, $3 \mathrm{kHz}$ spectral window, 1 transient and $1 \mathrm{~s}$ recycle delay.

${ }^{19} \mathrm{~F}$ 1D NMR. A one pulse $90^{\circ}(6.5 \mu \mathrm{s})$ pulse sequence was used with $0.08 \mathrm{~s}$ acquisition time, $75 \mathrm{kHz}$ spectral window 1 transient and $1 \mathrm{~s}$ recycle delay.

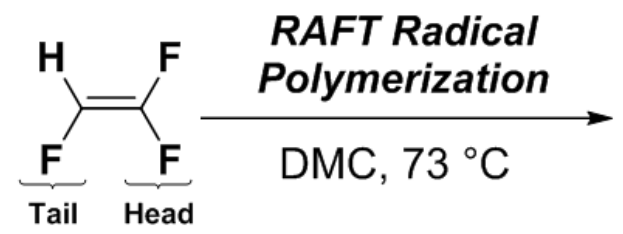

(T) $\quad(\mathrm{H})$

Initiator :

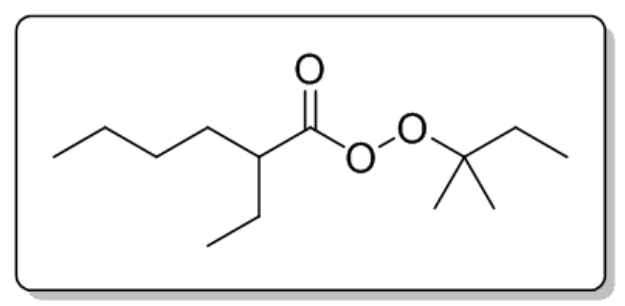

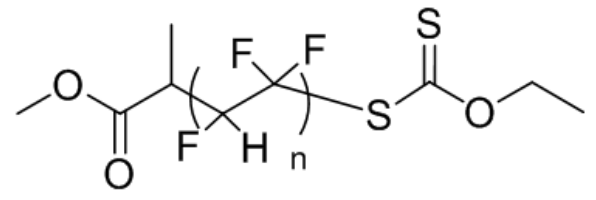

Chain Transfer Agent :

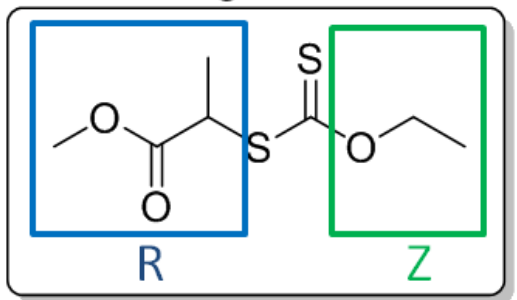

Figure 1. Scheme of the RAFT polymerization of TrFE, using tert-amyl peroxy-2-ethylhexanoate as initiator, O-ethyl-S-(1-methoxycarbonylethyl)dithiocarbonate as CTA and dimethylcarbonate as solvent.

Table 1. Experimental Conditions and Results for the RAFT Polymerization of TrFE

\begin{tabular}{|c|c|c|c|c|c|c|c|c|}
\hline Entry & {$[\mathrm{TrFE}]_{0}:[\mathrm{CTA}]_{0}:[\mathrm{I}]_{0}$} & $\begin{array}{c}\text { Polymerization } \\
\text { time (h) }\end{array}$ & $\begin{array}{c}\text { Conversion } \\
\text { (\%) }\end{array}$ & $\begin{array}{c}M_{\mathrm{n}^{1}} \\
\text { (g/mol) }\end{array}$ & $\bigoplus$ & CFH-XA ${ }^{2}(\%)$ & $\mathrm{CF}_{2}-\mathrm{XA}^{2}(\%)$ & $\begin{array}{c}\text { Irreversible } \\
\text { transfer }^{2} \\
(\%)\end{array}$ \\
\hline 1 & $100: 1: 0.2$ & 2 & 4.3 & 2,100 & 1.06 & 90.9 & 9.1 & 0 \\
\hline 2 & $100: 1: 0.2$ & 15 & 67 & 9,900 & 1.58 & 32.4 & 0 & 67.6 \\
\hline 3 & $50: 0: 0.2$ & 15 & 79 & 5,700 & 4.30 & 0 & 0 & 100 \\
\hline 4 & 20:1:0.1 & 0.5 & 2.5 & n.d. & n.d. & n.d. & n.d. & n.d. \\
\hline
\end{tabular}

Note: $n . a .=$ not applicable, polymer made by conventional radical polymerization in solution.

n.d. = not determined. Due to insufficient quantity of polymer recovered after polymerization, no SEC measurement was done on this sample. ${ }^{1}$ Calculated through GPC using PMMA standards. ${ }^{2}$ Calculated using NMR and equations S7 to S1O.

The theoretical DP of the PTrFE of entry 4 is 0.5 , however, estimation of the actual DP by ${ }^{1} \mathrm{H}$ and ${ }^{19} \mathrm{~F} N M R$ indicate a DP of 7 . These results suggest that only $7 \%$ of the CTA actually took part in the polymerization at that stage. 
${ }^{13} \mathrm{C} 1 \mathrm{D}$ NMR with ${ }^{1} \mathrm{H},{ }^{19} \mathrm{~F}$ and ${ }^{1} \mathrm{H}+{ }^{19} \mathrm{~F}$ Decoupling. A one pulse $90^{\circ}$ pulse sequence was used with $1.1 \mathrm{~s}$ acquisition time, $30 \mathrm{kHz}$ spectral window 4100 transient and $1 \mathrm{~s}$ recycle delay.

${ }^{19} \mathrm{~F} 2 \mathrm{D}$ NMR COSY with ${ }^{1} \mathrm{H}$ Decoupling. The cosygp pulse sequence from Bruker catalog was modified in order to include ${ }^{1} \mathrm{H}$ decoupling over the whole pulse sequence. The acquisition parameters were $1 \mathrm{~s}$ acquisition time, $75 \mathrm{kHz}$ spectral windows in $\mathrm{F} 2$ and in $\mathrm{F} 1,4$ transients and recycle delay of $1 \mathrm{~s}$. Processing involved a magnitude calculation phase correction in the F1 dimension.

${ }^{1} \mathrm{H}\left\{{ }^{13} \mathrm{C}\right\} 2 \mathrm{D}$ NMR HSQC with ${ }^{1} \mathrm{H}$ Decoupling. The hsqcetgpsi2 HSQC pulse sequence from Bruker catalog was modified in order to apply ${ }^{19} \mathrm{~F}$ decoupling over the whole pulse sequence. Acquisition parameters were $0.3 \mathrm{~s}$ acquisition time, $7.5 \mathrm{kHz}$ spectral window in $\mathrm{F} 2,25 \mathrm{~ms}$ acquisition time, $30.2 \mathrm{kHz}$ spectral window in $\mathrm{F} 1,{ }^{1} \mathrm{~J}_{\mathrm{CH}}=152$ $\mathrm{Hz}$, garp decoupling for ${ }^{13} \mathrm{C}, 8$ transients and recycle delay of $1 \mathrm{~s}$. Processing involved an exponential window multiplication in both dimensions.

${ }^{19} \mathrm{~F}\left\{{ }^{13} \mathrm{C}\right\} 2 \mathrm{D}$ NMR HSQC with ${ }^{1} \mathrm{H}$ Decoupling. The pulse sequence described by Li et al. ${ }^{20}$ (2D NMR studies of a model for Krytox ${ }^{\circledR}$ perfluoropolyethers) was written from scratch for a Bruker system, the only modifications being ${ }^{1} \mathrm{H}$ decoupling over the whole pulse sequence, ${ }^{13} \mathrm{C}$ decoupling performed with nested loops using $0.5 \mathrm{~ms}$ and $1 \mathrm{~ms}$ chirped adiabatic pulses with $30 \mathrm{kHz}$ bandwidth in order to desynchronize and minimize decoupling artefacts and echo-antiecho quadrature detection in F1. Acquisition parameters were $83 \mathrm{~ms}$ acquisition time and $75 \mathrm{kHz}$ spectral window in $\mathrm{F} 2,99 \mathrm{~ms}$ acquisition time and $10 \mathrm{kHz}$ spectral window in $\mathrm{F} 1,{ }^{1} \mathrm{~J}_{\mathrm{CF}}=260 \mathrm{~Hz}, 16$ transients and recycle delay of $1 \mathrm{~s}$.

Processing involved linear prediction of an exponential window multiplication in both dimensions and a magnitude calculation phase correction in the F1 dimension.

${ }^{2} \mathrm{~J}_{\mathrm{CF}}=30 \mathrm{~Hz}$ was used for the ${ }^{2 \mathrm{~J}}{ }^{19} \mathrm{~F}\left\{{ }^{13} \mathrm{C}\right\} 2 \mathrm{D}$ NMR HSQC with ${ }^{1} \mathrm{H}$ Decoupling.

\section{Results and discussion}

Investigating the ${ }^{19} \mathrm{~F}$ NMR of PTrFE made by RAFT is challenging for two reasons: tacticity and chain defects (reverse additions). PTrFE possesses $\mathrm{CFH}(\mathrm{T})$ and $\mathrm{CF}_{2}(\mathrm{H})$ groups producing resonances in two different zones. The $\mathrm{CF}_{2}$ resonances are found at chemical shifts ranging from -110 to $-140 \mathrm{ppm}$ while those of the $\mathrm{CFH}$ signals are in the -200 to -220 ppm region. Moreover, the stereogenic CFH groups often split the signals of the neighbouring atoms. For example, the configuration of the two $\mathrm{CFH}$ groups in a $-\mathrm{CFH}-\mathrm{CF}_{2}-\mathrm{CFH}$ - sequence will significantly influence the $\mathrm{CF}_{2}$ signals. An isotactic triad will produce a meso configuration for the central $\mathrm{CF}_{2}$ with two non-equivalent fluorine atoms $\left(F_{a}\right.$ and $\left.F_{b}\right)$ and the ${ }^{19} F\left\{{ }^{1} H\right\}$ NMR pattern of the $\mathrm{CF}_{2}$ group will be an $A B$ system with a strong ${ }^{2} J_{F F}$ geminal coupling (Figure S1). In contrast, a syndiotactic structure will generate a racemic configuration for the $\mathrm{CF}_{2}$ group where the fluorine atoms $\left(\mathrm{F}_{\mathrm{c}}\right)$ are isochronous and their signal will appear as a broad singlet since the ${ }^{3} \mathrm{~J}_{\mathrm{FF}}$ coupling (from 5 to $30 \mathrm{~Hz}$ ) on the backbone polymer signal is too small relative to the resonance linewidth (Figure S1). This kind of splitting pattern has been studied and described in previous reports and explains the fact that the resonances of both $\mathrm{CF}_{2}$ and $\mathrm{CFH}$ groups lead to complex signals. ${ }^{14,21}$ This article will rather focus on the RAFT chain ends brought by the RAFT process.

Another complexity of the ${ }^{19} \mathrm{~F}$ NMR spectrum arises from the reverse additions that occur during polymerisation (see Introduction). ${ }^{21}$ The different macroradicals resulting from the regular and reverse monomer additions are described in Figure S2. The head-to-head $(\mathrm{HH})$ additions are minor $(13.5 \%$ according to

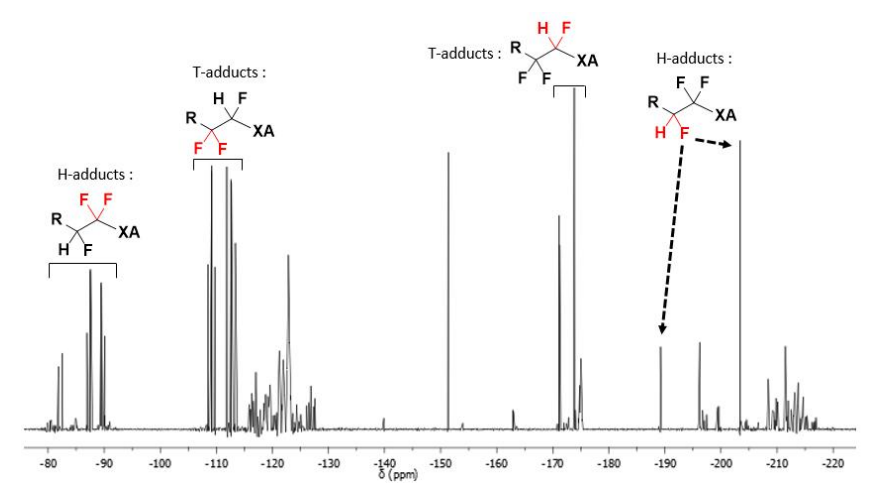

Figure 2. ${ }^{19} \mathrm{~F}\left\{{ }^{1} \mathrm{H}\right\}$ spectrum of PTrFE (yield $=4.3 \%$ ) made by RAFT (Entry 1, Table 1) recorded in acetone-d6 (where XA stands for $\mathrm{SC}(\mathrm{S}) \mathrm{XEt}$ and $\mathrm{R}$ for $\left.\mathrm{CH}_{3} \mathrm{O}(\mathrm{C}=\mathrm{O}) \mathrm{CH}\left(\mathrm{CH}_{3}\right)\right)$ ).

Tonelli et $\mathrm{al}^{13}$ ) but play an important role on the PTrFE properties (e.g. crystallinity and electroactivity). This article deals with the assignment of the different chain-end groups of PTrFE synthesized using RAFT polymerisation. A study of the TrFE RAFT polymerisation mechanism will be reported elsewhere. ${ }^{22}$

The complete assignments of the chain-end signals for the PTrFE product made by RAFT was made possible by a set of $1 \mathrm{D}$ and $2 \mathrm{D}{ }^{1} \mathrm{H}$, ${ }^{19} \mathrm{~F}$ and ${ }^{13} \mathrm{C}$ NMR experiments.

\section{C.1 Monoadducts determination}

The ${ }^{19} \mathrm{~F}\left\{{ }^{1} \mathrm{H}\right\}$ NMR spectrum (Figure 2 ) of a PTrFE made by RAFT polymerisation stopped at low conversion (Entry 1, Table 1, 4.3\%) shows numerous resonances, and in particular several groups of sharp peaks. These signals reveal the presence of two types of monoadducts (i.e. product resulting from the reaction of only one TrFE unit with the $R^{R}$ radical of the CTA followed by transfer to another (TA). Several isomers can be noted. The first monoadduct results from the $\mathrm{R}^{\cdot}$ addition to the TrFE tail (regular addition leading to $\mathrm{R}-\mathrm{CHF}-\mathrm{CF}_{2}-\mathrm{XA}$, called $\mathrm{H}$-adduct), whereas the second one results from the $\mathrm{R}^{\cdot}$ addition to the TrFE head (leading to $\mathrm{R}-\mathrm{CF}_{2}-\mathrm{CFH}-\mathrm{XA}$ and called T-adduct). The possible structures of these monoadducts are shown in Figure S3. The two stereocenters ( $R$ is chiral) on the molecules produce four different stereoisomers per type of monoadduct (two enantiomeric pairs of diastereoisomers) with relatively complex NMR splitting patterns.

The monoadduct resonances are easily recognizable as they appear as sharp peaks, contrarily to the broad polymer signals. In addition, the presence of the xanthate end-group strongly shifts the resonances downfield as reported earlier. ${ }^{16,23}$ Consequently, the $\mathrm{CF}_{2}$ signals of the $\mathrm{H}$-adducts are found at around -80 to $-90 \mathrm{ppm}$ while those of the T-adducts are located between -105 and -115 ppm (Figure 2). Similarly, the $\mathrm{CFH}$ signals of the $\mathrm{H}$ - and T-adducts are located between -185 and -205 ppm and between -170 and -175 ppm, respectively. All of these regions contain two sets of resonances, each one corresponding to one diastereoisomer. The $\mathrm{CFH}$ resonance integral allows the determination of each diastereisomer pair relative proportion (Equations S1 to S4). For both adduct families, the most abundant diatereoisomer should correspond to the RR/SS enantiomeric pair as they present the methyl and fluorine atom in anti-positions (whereas they are syn in the RS/SR couples). This consideration was used to assign the NMR signals to the different diastereisomers (see Table 2, and Figure S4 to Figure S11).

The 3-bond correlations between the $\mathrm{CFH}$ and $\mathrm{CF}_{2}$ fluorine atoms visible on the ${ }^{19} \mathrm{~F}$ COSY spectrum (Figure S12 and Figure S13) allowed the assignment of each signal to a unique enantiomer couple (see Table 2). The presence of the CFH stereocentre makes both fluorine atoms in the $\mathrm{CF}_{2}$ group ( $\mathrm{F}_{1}$ and $\mathrm{F}_{2}$, Table 2 ) non-equivalent, yielding an $A B X$ pattern (i.e. doublets of doublets for each $F$ atom, in Figure 


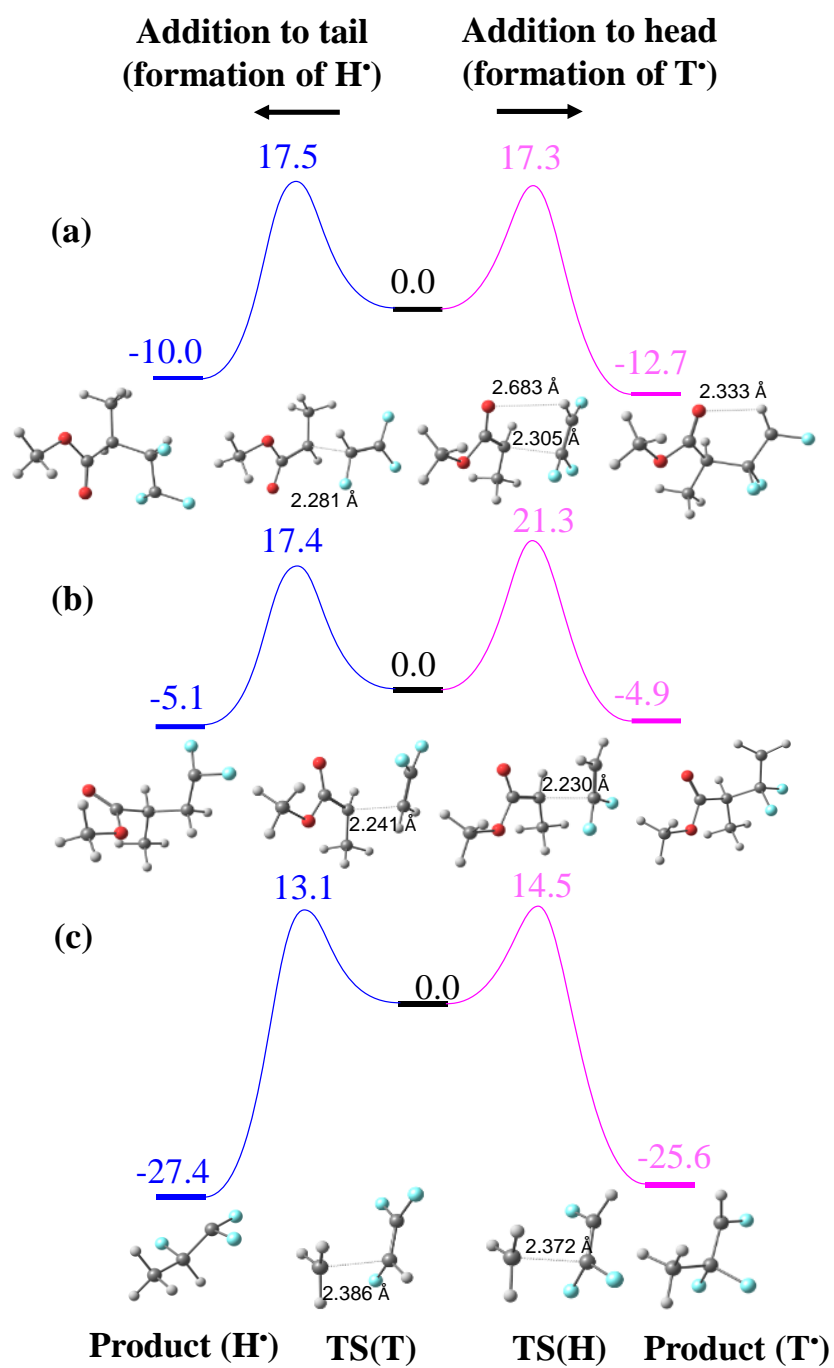

Figure 3: Energy profiles (values are standard free energies at $298 \mathrm{~K}_{\text {in }} \mathrm{kcal} \mathrm{mol}^{-1}$ ) and views of the optimized structures for the starting compounds, transition states and products of radical additions to monomers. (a) Addition of ${ }^{\circ} \mathrm{CH}\left(\mathrm{CH}_{3}\right) \mathrm{COOCH}_{3}$ to $\mathrm{CHF}=\mathrm{CF}_{2}$. (b) Addition of ${ }^{\circ} \mathrm{CH}\left(\mathrm{CH}_{3}\right) \mathrm{COOCH}_{3}$ to $\mathrm{CH}_{2}=\mathrm{CF}_{2}$. (c) Addition of $\mathrm{CH}_{3}{ }^{\circ}$ to $\mathrm{CHF}=\mathrm{CF}_{2}$.

$\mathrm{S} 4$ to Figure $\mathrm{S} 7$ for the $\mathrm{H}$-adducts and Figure $\mathrm{S} 8$ to Figure $\mathrm{S} 11$ for the $\mathrm{T}$-adducts). The geminal $\mathrm{F}$ atoms are strongly coupled, with ${ }^{2 \mathrm{~J}_{\mathrm{F}-\mathrm{F}}}$ around $236-237 \mathrm{~Hz}$ and $260-263 \mathrm{~Hz}$ for the $\mathrm{H}$-adduct (Figures S4 and S6) and T-adduct (Figures S8 and S11), respectively. The CFH resonance is also complex due to the ${ }^{3} \mathrm{~F}_{\mathrm{F}-\mathrm{F}}$ couplings with $\mathrm{F}_{1}$ and $\mathrm{F}_{2}$ (see Figures S5 and S7 for the $\mathrm{H}$-adducts; Figures S9 and S10 for the T-adducts). The difference of the ${ }^{3} \mathrm{~J}_{\mathrm{F}-\mathrm{F}}$ values in the 2 diastereoisomer couples (Table 2) is worth noting. This is ascribed to the different shielding effect of the $\mathrm{CFH}$ and $\mathrm{CH}_{3}$ groups on $\mathrm{F}_{1}$ and $\mathrm{F}_{2}$. In the $\mathrm{RS} / \mathrm{SR}$ diastereoisomers (for both $\mathrm{H}$ - and T-adducts), both $\mathrm{CFH}$ and $\mathrm{CH}_{3}$ are syn, resulting in a stronger influence on $\mathrm{F}_{1}$ or $\mathrm{F}_{2}$ compared to the $\mathrm{RR} / \mathrm{SS}$ diastereoisomers. Finally, a $2 \mathrm{D}^{1} \mathrm{H}-{ }^{19} \mathrm{~F}$ heterocosy experiment (Figures S14-S16) allowed us to assign the ${ }^{1} \mathrm{H}$ NMR resonances of the $\mathrm{CFH}, \mathrm{CH}$ and $\mathrm{CH}_{3}$ groups. To confirm the above assignments, the chemical shifts, ${ }^{2} \mathrm{~J}_{\mathrm{F}-\mathrm{F}}$ and ${ }^{3} \mathrm{~J}_{\mathrm{F}-\mathrm{F}}$ constants determined from the ${ }^{19} \mathrm{~F}$ and ${ }^{1} \mathrm{H}$ spectra (Table 2 ) were used in the simulation software gNMR and the ${ }^{19} \mathrm{~F}\left\{{ }^{1} \mathrm{H}\right\}$ spectra were reconstructed. The simulated and experimental spectra showed good agreement (Figure S17 and S18), confirming the reliability of the ABX system solving method. ${ }^{24}$

Surprisingly, the T-adducts seemed more abundant than the $\mathrm{H}$ adducts (Table 2, Equation S5 and S6). This may be partly explained by the slower T-adduct reactivation. Moreover, the addition of the CTAXA $R^{\prime}$ radical to the TrFE tail or head is not equiprobable. In the present case, the acrylic radical derived from CTAXA may also react preferentially to the TrFE head (leading to T-adducts). In order to cast light on this question, the barriers for the addition of the acrylate radical from CTAXA to both monomer ends were calculated using DFT. The chosen computational level is identical to that used in the previous investigations of both propagation $(\mathrm{HT}, \mathrm{HH}, \mathrm{TH}$ and $\mathrm{TT}$ additions) and chain transfer (degenerate $\mathrm{H}-\mathrm{H}$ and T-T and nondegenerate $\mathrm{H}-\mathrm{T}$ ) in the RAFT polymerisations of VDF18 (see computational details in the supporting information).

The results (Figure 3a) confirm that the addition to the TrFE head end is more favored: at $25^{\circ} \mathrm{C}$, the free energy of activation is $0.2 \mathrm{kcal} \mathrm{mol}^{-}$ ${ }^{1}$ lower than for the corresponding addition to the tail end. At $70{ }^{\circ} \mathrm{C}$ (temperature used for the polymerisation), both barriers are slightly higher (18.9 vs. $19.1 \mathrm{kcal} \mathrm{mol}^{-1}$, respectively) because of a negative activation entropy but a $0.2 \mathrm{kcal} \mathrm{mol}^{-1}$ bias in favor of the head end attack remains. On the basis of this $\Delta\left(\Delta G^{\ddagger}\right)$, the expected $H / T$ ratio at $70{ }^{\circ} \mathrm{C}$ is $57: 43$. In order to reproduce the observed $\mathrm{H} / \mathrm{T}$ ratio (79:21), the $\Delta\left(\Delta G^{\ddagger}\right)$ should be $\sim 0.4 \mathrm{kcal} \mathrm{mol}^{-1}$ and we consider this agreement as satisfactory. The most interesting point is the reason leading to this preference, because attack of the two TrFE carbon atoms by other radicals (e.g. the head and tail radicals of the growing PTrFE chain) occurs preferentially at the tail end)

The reason of this discrepancy is clear when viewing the optimized geometries of the transition state and product for the two pathways. Whereas the tail-end attack does not display any interaction other than the incipient C...C bond, the head-end attack also shows a short

Table 2 : Chemical shifts and coupling constants of the $\mathrm{H}$-adduct and T-adduct of TrFE and O-ethyl-S-(1-methoxycarbonyl)ethyldithiocarbonate (CTA-XA).

\begin{tabular}{|c|c|c|c|c|c|c|c|c|c|}
\hline & & Molar & $\delta \mathrm{CFH}$ & ppm) & $\delta \mathrm{CF}_{2}$ & opm) & & & $\mathrm{Hz})$ \\
\hline & & fraction (\%) & $\mathrm{H}$ & $\mathrm{F}$ & $\mathrm{F}_{1}$ & $\mathrm{~F}_{2}$ & & With $F_{1}$ & With $F_{2}$ \\
\hline $\mathrm{H}$-adducts & $\mathrm{RR} / \mathrm{SS}$ & 69 & $\begin{array}{c}\mathrm{CFH}: 5.53 \\
\mathrm{CH}: 3.14 \\
\mathrm{CH}_{3}: 1.33\end{array}$ & $\begin{array}{c}-203.3 \\
\text { Figure S5 }\end{array}$ & $\begin{array}{c}-87.2 \\
\text { Figure S4 }\end{array}$ & $\begin{array}{c}-89.7 \\
\text { Figure S4 }\end{array}$ & 237 & 16 & 16.4 \\
\hline (29 mol\%) & $\mathrm{RS} / \mathrm{SR}$ & 31 & $\begin{array}{l}\mathrm{CFH}: 5.33 \\
\mathrm{CH}: 3.14 \\
\mathrm{CH}_{3}: \text { n.d. }\end{array}$ & $\begin{array}{c}-189.1 \\
\text { Figure S7 }\end{array}$ & $\begin{array}{c}-82.0 \\
\text { Figure S6 }\end{array}$ & $\begin{array}{c}-89.6 \\
\text { Figure S6 }\end{array}$ & 236 & 15.5 & 17.2 \\
\hline T-adducts & $\mathrm{RR} / \mathrm{SS}$ & 56 & $\begin{array}{l}\mathrm{CFH}: 7.13 \\
\mathrm{CH}: 3.48 \\
\mathrm{CH}_{3}: 1.41\end{array}$ & $\begin{array}{c}-173.8 \\
\text { Figure S10 }\end{array}$ & $\begin{array}{c}-109.3 \\
\text { Figure S11 }\end{array}$ & $\begin{array}{c}-112.9 \\
\text { Figure S11 }\end{array}$ & 263 & 17.7 & 16.9 \\
\hline (71 mol\%) & $\mathrm{RS} / \mathrm{SR}$ & 44 & $\begin{aligned} & \mathrm{CFH}: 7.22 \\
& \mathrm{CH}: \text { n.d. } \\
& \mathrm{CH}_{3}: 1.41\end{aligned}$ & $\begin{array}{c}-171.1 \\
\text { Figure S9 }\end{array}$ & $\begin{array}{c}-108.8 \\
\text { Figure S8 }\end{array}$ & $\begin{array}{c}-112.1 \\
\text { Figure S8 }\end{array}$ & 260 & 17.2 & 15.5 \\
\hline
\end{tabular}

Note: $n . d .=$ non determined. The corresponding correlation spot on the $2 \mathrm{D}^{1} \mathrm{H}$ COSY is hidden by signal of the $\alpha$-chain end signal. Nonetheless, the chemical shifts can be estimated to be around 1.3-1.4 ppm for the $\mathrm{CH}_{3}$ and 3.4-3.5 ppm for the $\mathrm{CH}$ group. 


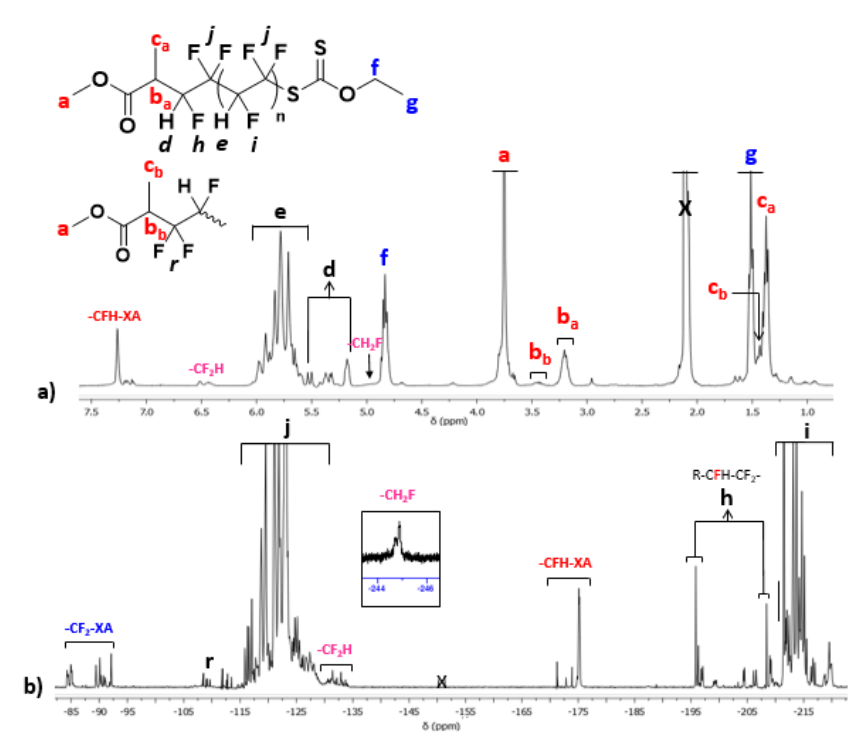

Figure 4. a) ${ }^{1} \mathrm{H}\left\{{ }^{19} \mathrm{~F}\right\}\left\{{ }^{13} \mathrm{C}\right\}$ and b) ${ }^{19} \mathrm{~F}\left\{{ }^{1} \mathrm{H}\right\}\left\{{ }^{13} \mathrm{C}\right\}$ spectra in acetone-d6 of PTrFE made by RAFT (Entry 4, Table 1).

contact ( $\mathrm{H}$-bond) between the $\mathrm{H}$ atom of the monomer $\mathrm{CHF}$ group and the carbonyl oxygen atom of the attacking radical. This $\mathrm{H}$-bond is already established at the TS level $(2.683 \AA)$ and is further strengthened in the product $(2.333 \AA)$. This interaction obviously stabilizes the molecule and thus introduces a bias in favor of the head-end attack. For the tail-end addition pathway, on the other hand, the $\mathrm{H}$ atom is unsuitably placed to establish a strong $\mathrm{H}$-bond with the carbonyl oxygen atom because the resulting ring would be too strained. A relatively strong $\mathrm{H}$-bond in this system is not surprising when considering the electron withdrawing power of the three $\mathrm{F}$ atoms, significantly reducing the electron density on the monomer $\mathrm{H}$ atom. In order to further support this rationalization, additional calculations were carried out on another two initiating systems. The first one (Figure $3 \mathrm{~b}$ ) is the addition of the same acrylate radical to VDF, for which $\mathrm{R}_{0}-\mathrm{CF}_{2} \mathrm{CH}_{2}{ }^{\circ}$ (product of the addition to the head-end) lacks a $\beta$-F substituent and hence the $\mathrm{C}-\mathrm{H}$ bonds should display lower tendency to act as proton donors in $\mathrm{H}$-bonding. Previous calculations on the VDF RAFT polymerisation were limited to the exchange of head and tail model radical on the CTA, as well as on the regular and reverse monomer additions to the same model radicals ${ }^{18}$, but did not address the addition of the CTA primary radical to the VDF monomer. The second initiating system (Figure 3c) consists of the addition to TrFE of the simpler methyl radical, which lacks the carbonyl function. The results for both systems show that the preferred addition is indeed, as expected, to the monomer tailend. In particular, a comparison between Figures $3 \mathrm{a}$ and $3 \mathrm{~b}$ shows that the barrier to the tail-end additions ( $\mathrm{CHF}$ for $\mathrm{TrFE}$ and $\mathrm{CH}_{2}$ for VDF) are essentially identical, whereas the addition to the head $\mathrm{CF}_{2}$ group requires a much greater barrier for VDF $\left(21.3 \mathrm{kcal} \mathrm{mol}^{-1}\right.$, i.e. $4.0 \mathrm{kcal} \mathrm{mol}^{-1}$ higher than for TrFE). This preferential CTA primary radical addition to the VDF monomer tail was in fact experimentally confirmed by our group in a recent publication. ${ }^{17}$ The barriers for the addition of $\mathrm{CH}_{3} \cdot$ to TrFE are lower than those for the addition of $\mathrm{CH}_{3} \mathrm{CH}^{*} \mathrm{COOCH}_{3}$, in agreement with the greater reactivity of the $\mathrm{CH}_{3}{ }^{\cdot}$ radical, with a difference of $1.4 \mathrm{kcal} \mathrm{mol}^{-1}$ in favour or the tail-end addition and lead to greater thermodynamic gains.

\section{C.2 Assignment of the $\alpha$-chain-end}

There are five possible structures for the $\alpha$-chain-end (Figure S19). Chains can be initiated by radicals derived from the tert-amyl peroxy2-ethylhexanoate thermal decomposition, by the DMC solvent after $\mathrm{H}$-atom abstraction by the very reactive $\mathrm{PTrFE} \cdot$ radical, or by the CTA R-group. The asymmetric initiator can produce two different radicals and the carboxylate radical may undergo decarboxylation depending on the temperature. The initiator-generated chain ends could be attributed to the low intensity resonances observed between 0.85 and $1.7 \mathrm{ppm}$ and partly ovelapping with the signals of the CTA Rgroup. This overlap prevented their quantification.

Moreover, as mentioned above, the initiating radical can add to either the tail ( $\mathrm{CHF}$, noted R-PTrFE $)$ or the head of TrFE ( $\mathrm{CF}_{2}$ noted $\mathrm{R}$ $\mathrm{PTrFE}_{\mathrm{H}}$ ). In addition to this regioisomerism, as in the case of monoadducts, the presence of asymmetric carbons results in the generation of pairs of enantiomers and diastereoisomers. The number of stereoisomers is higher than in the case of the monoadducts and it is function of the number of stereocenters $(n)$ : $\left(2^{n}\right)$ (Figure S20).

Even with the use of ${ }^{19} \mathrm{~F}$ decoupling, the ${ }^{1} \mathrm{H}$ resonances were too broad to clearly distinguish each diastereoisomer splitting pattern (Figure 4a). Nevertheless, the CTAXA R-group methyl resonance ( $c_{a}$, Figure 4a) was assigned to the signal at $1.37 \mathrm{ppm}$ in the ${ }^{1} \mathrm{H}\left\{{ }^{19} \mathrm{~F}\right\}$ spectrum. The COSY ${ }^{1} \mathrm{H}\left\{{ }^{19} \mathrm{~F}\right\}$ spectrum (Figure S21) shows clear correlations of this signal with that of the methanetriyl group (b) at $3.2 \mathrm{ppm}$, and with that of the CFH moiety $\left(\mathrm{c}_{1-4}\right) 4$ bonds away. This 4bond correlation system is observed as 4 spots ( $c_{1-4}$, Figure S21)

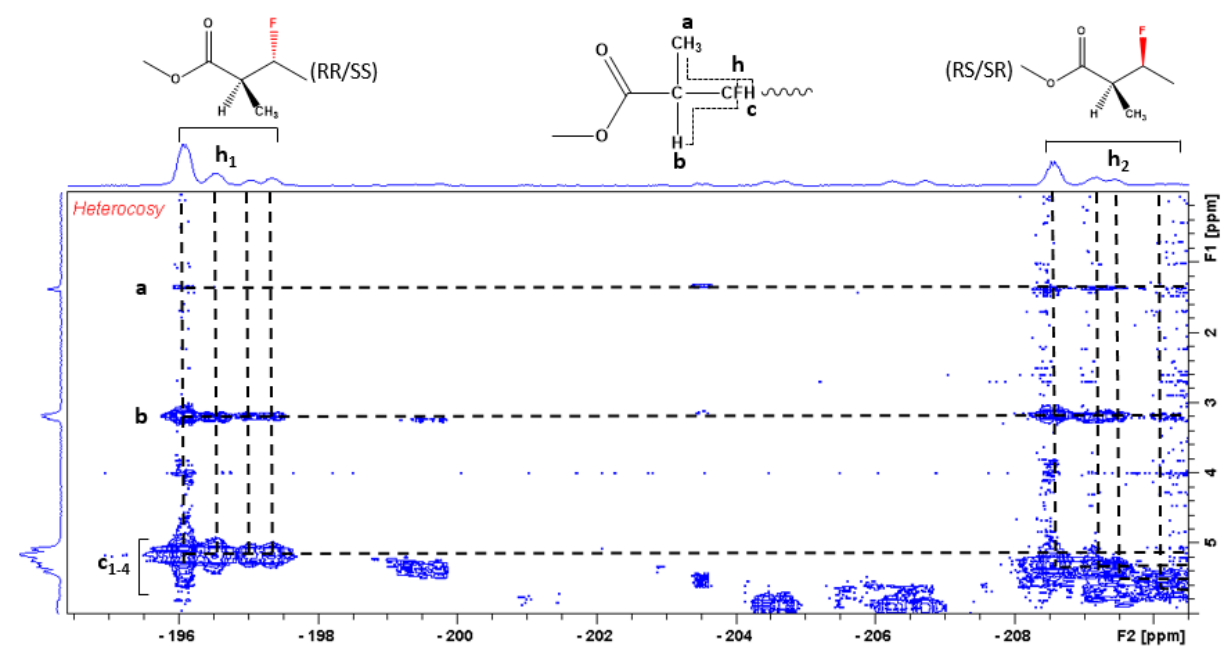

Figure 5. Zoom of the $[0-6 \mathrm{ppm} ;-194.5--210.5 \mathrm{ppm}]$ region (RT-PTrFE correlation zone) of the ${ }^{19} \mathrm{~F}-{ }^{1} \mathrm{H}$ Heterocosy spectrum of PTrFE made by RAFT recorded in acetone d-6 (Entry 4, Table 1). 
Table 3. Assignments of the ${ }^{1} \mathrm{H}$ and ${ }^{19} \mathrm{~F}$ signals of the R-PTrFE $\alpha$-chain end.

\begin{tabular}{|c|c|c|c|c|}
\cline { 2 - 5 } \multicolumn{1}{c|}{} & \multicolumn{3}{c|}{${ }^{1} \mathrm{H}(\mathrm{ppm})$} & ${ }^{19} \mathrm{~F}(\mathrm{ppm})$ \\
\cline { 2 - 5 } \multicolumn{1}{c|}{} & $\mathrm{CH}_{3}(\mathrm{a})$ & $\mathrm{CH}(\mathrm{b})$ & $\mathrm{CFH}(\mathrm{c})$ & $\mathrm{CFH}(\mathrm{h})$ \\
\hline \multirow{4}{*}{ RR;SS } & 1.37 & 3.20 & 5.17 & -196.1 \\
\cline { 2 - 5 } & 1.37 & 3.20 & 5.18 & -196.5 \\
\cline { 2 - 5 } & 1.37 & 3.20 & 5.18 & -197.0 \\
\cline { 2 - 5 } & 1.37 & 3.20 & 5.18 & -197.3 \\
\hline \multirow{4}{*}{ RS; SR } & 1.37 & 3.20 & 5.31 & -208.6 \\
\cline { 2 - 5 } & 1.37 & 3.20 & 5.35 & -209.1 \\
\cline { 2 - 5 } & 1.37 & 3.20 & 5.37 & -209.5 \\
\cline { 2 - 5 } & 1.37 & 3.20 & 5.53 & -210.2 \\
\hline
\end{tabular}

between 5.16 and $5.51 \mathrm{ppm}$ corresponding to the 4 couples of enantiomers generated by the first 3 stereocentres (Figure S20).

The ${ }^{1} \mathrm{H}-{ }^{19} \mathrm{~F}$ heterocosy spectrum (Figure 5 ) shows two groups of signals for the CFH fluorine atom $\left(h_{1}\right.$ and $h_{2}$ around -197 and -209 ppm respectively) corresponding to 2 pairs of enantiomers, and correlating through 2, 3 and 4 bonds with the $c_{1}-c_{4}, b$ and a protons (around 5.3, 3.2 and.37 ppm, respectively).

The integration of these fluorine signals revealed $h_{1}$ as the signal of the most abundant stereoisomer (60.2\%). It was thus assigned to the $\mathrm{RR} / \mathrm{SS}$ enantiomer couple following the reasoning used previously for the assignment of the monoadduct signals. It is important to point out that the relative abundance of the RR/SS and RS/SR structures of this R-PTrFE end-group is in good agreement with the corresponding relative abundance determined for the $\mathrm{T}$-adduct.

Four resonances were found for each of these groups of fluorine signals (Figure 5) indicating the existence of 8 different enantiomer couples. This observation was confirmed by the ${ }^{19} \mathrm{~F}-{ }^{13} \mathrm{C}$ gHSQC spectrum (Figure S22 and Figure S23) which shows 4 different carbon resonances for each fluorine signals. These relatively complex NMR signals can only be explained by considering 4 stereocentres, which underlines the strong influence of stereochemical configurations on the PTrFE ${ }^{19} \mathrm{~F}$ NMR signals. Table 3 summarises the chemical shifts and assignments of the ${ }^{1} \mathrm{H}$ and ${ }^{19} \mathrm{~F}$ NMR signals of these PTrFE $\alpha$-chain end.

\section{C.3 Assignment of the $\omega$-chain-end}

Two types of characteristic $\omega$-chain-ends can be produced: dead chains arising from irreversible transfer and dormant chains issued from RAFT polymerisation. Dead chains generated by irreversible transfer ( $\mathrm{H}$-abstraction) reactions (to $\mathrm{DMC}$, monomer, or polymer) lead to $-\mathrm{CF}_{2} \mathrm{H}$ or $-\mathrm{CFH}_{2}$ end groups. The ${ }^{1} \mathrm{H}$ NMR signal (broad triplet at $6.5 \mathrm{ppm},{ }^{2} \mathrm{~J}_{\mathrm{H}-\mathrm{F}}=48 \mathrm{~Hz}$, Figure 4) of $-\mathrm{CF}_{2} \mathrm{H}$ end-group was already reported by Soulestin et al. ${ }^{25}$ as these chain ends, which are not specific to RAFT polymerisation, are also formed during conventional radical polymerisation. $2 \mathrm{D}$ experiments (Heterocosy and gHSQC)

Table 4. Assignments of the ${ }^{1} \mathrm{H}$ and ${ }^{19} \mathrm{~F}$ NMR signals of the R-PTrFE $\alpha$-chain end

\begin{tabular}{|c|c|c|c|c|c|c|}
\hline \multirow[t]{2}{*}{ CFH-XA } & \multicolumn{3}{|c|}{$\underbrace{F_{6}}_{F_{4} F_{5}}$} & \multicolumn{2}{|c|}{$\underbrace{F_{3} F_{2}}_{F_{6}}$} & \\
\hline & F1 & $\mathrm{F} 2$ & F3 & F4 & F5 & F6 \\
\hline TH (racemic) & -172.7 & -118.8 & -118.8 & I & I & -212.2 \\
\hline TH (meso) & -175.0 & -116.2 & -122.2 & / & / & -211.8 \\
\hline TH (meso) & -175.2 & -116.6 & -122.9 & / & I & -212.4 \\
\hline HH (Figure S25) & 175.1 & -116.7 & -123.4 & -121.1 & -127.1 & -209.8 \\
\hline HH (Figure S26) & 175.1 & -116.7 & -121.9 & -117.3 & -126.5 & -199.1 \\
\hline HH (Figure S27) & 175.1 & -166.8 & -122.0 & -120.5 & -127 & -210.1 \\
\hline HH (Figure S28) & 175.1 & -116.5 & -123.1 & -118.7 & -126.9 & -199.2 \\
\hline \multirow[t]{2}{*}{$\mathrm{CF}_{2}-\mathrm{XA}$} & \multicolumn{6}{|c|}{$\underbrace{F_{4} F_{1} F_{2}}_{F_{3}} \quad H T: \underbrace{F_{F}}_{F A} \underbrace{X A}_{F_{1} F_{2}}$} \\
\hline & $\mathrm{F} 1$ & $\mathrm{~F} 2$ & F3 & $\mathrm{F} 4$ & F5 & F6 \\
\hline HT & -84.7 & -89.6 & -204.4 & I & 1 & I \\
\hline HT & -84.5 & -89.7 & -204.2 & / & / & / \\
\hline $\mathrm{HT}$ & -84.9 & -89.6 & -205.2 & I & I & I \\
\hline $\mathrm{HT}$ & -85.0 & -91.4 & -201.2 & I & I & I \\
\hline TT & -84.5 & -90.6 & -206.5 & -214.7 & I & I \\
\hline $\mathrm{TT}$ & -84.5 & -90.6 & -206.5 & -214.3 & / & I \\
\hline $\mathrm{TT}$ & -84.6 & -90.3 & -206.1 & -213.3 & / & / \\
\hline $\mathrm{TT}$ & -84.6 & -90.3 & -206.0 & -213.3 & / & I \\
\hline $\mathrm{TT}$ & -84.7 & -89.6 & -212.7 & -219.0 & / & / \\
\hline $\mathrm{TT}$ & -84.9 & -98.8 & -212.5 & -219.5 & I & I \\
\hline
\end{tabular}




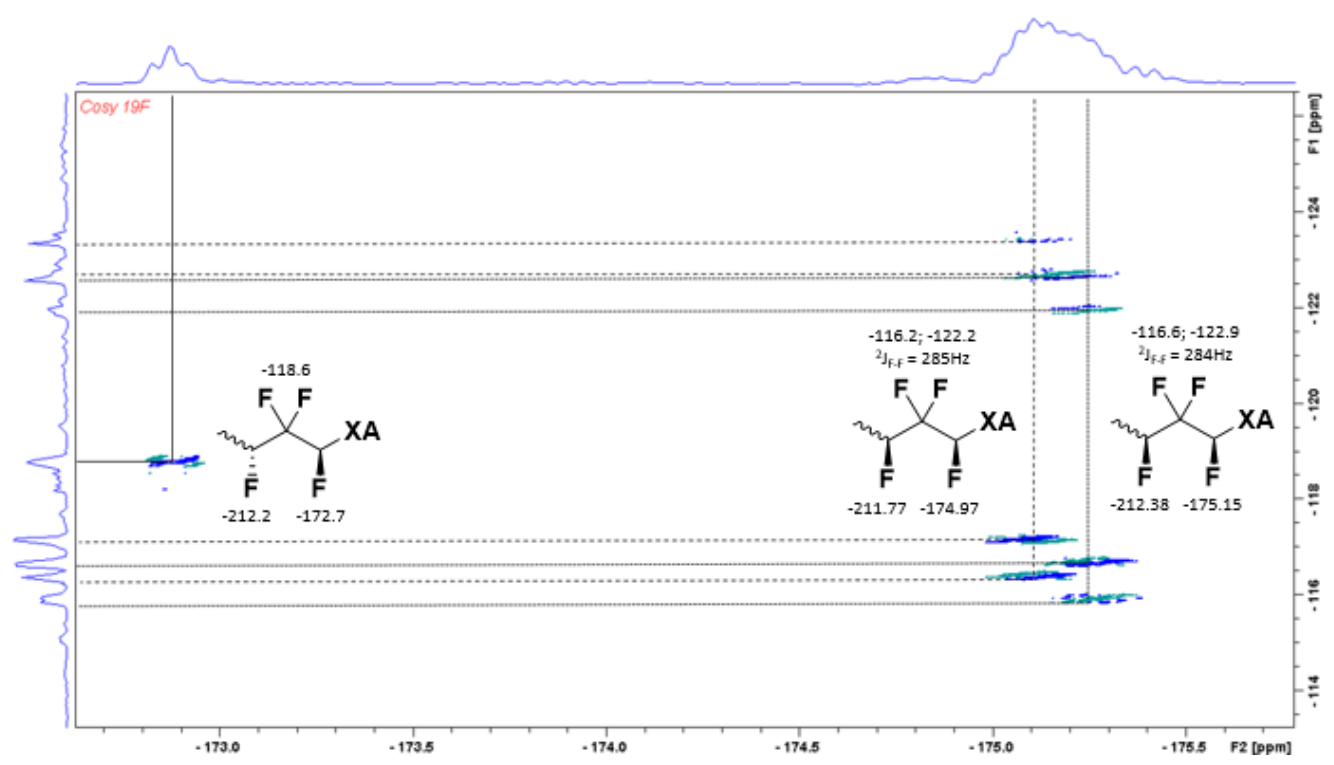

Figure 6. Zoom of the $[-172.6--175.8 \mathrm{ppm} ;-113.5--126.5 \mathrm{ppm}]$ region of the ${ }^{19} \mathrm{~F}\left\{{ }^{1} \mathrm{H}\right\}$ COSY spectrum of PTrFE made by RAFT (Entry 4, Table 1 ) showing the CFH/CF 2 correlations of the $[\mathrm{TH}]-\mathrm{XA}$ chain end.

allowed the identification of the corresponding fluorine and carbon resonances as a multiplet between -130.2 and $-134.6 \mathrm{ppm}$ and a singlet at $110.7 \mathrm{ppm}$ in the ${ }^{19} \mathrm{~F}$ and ${ }^{13} \mathrm{C}$ NMR spectra, respectively. The PTrFE- $-\mathrm{CFH}_{2}$ chain end ${ }^{19} \mathrm{~F}$ NMR resonance, however, has not been previously assigned. The weak resonance observed at $-244.6 \mathrm{ppm}$ is assigned to this chain end in agreement with Dolbier, ${ }^{26,27}$ who reported a similar chemical shift for the $-\mathrm{CFH}_{2}$ group of 1,1,2trifluoroethane. The corresponding proton was found at $4.98 \mathrm{ppm}$ (doublet of triplets, ${ }^{2} \mathrm{~J}_{\mathrm{H}-\mathrm{F}}=45.9 \mathrm{~Hz},{ }^{3} \mathrm{~J}_{\mathrm{H}-\mathrm{F}}=12.7 \mathrm{~Hz}$ ).

The dormant chains, i.e. the xanthate terminated chain, produce very complex signals because of the chain inversions occurring during the polymerisation of TrFE.

To identify these chain ends, the ${ }^{19} \mathrm{~F}$ NMR spectra of PTrFE synthesized by conventional radical and RAFT polymerisations (Figure S24) are compared. The signals ranging between -172 and $176 \mathrm{ppm}$ are assigned to the -CFH-XA group while those between 84.2 and $-91.5 \mathrm{ppm}$ to the $-\mathrm{CF}_{2}-\mathrm{XA}$ group.

In each case, several relatively broad peaks can be observed. Other sharp resonances are due to the monoadducts that have been assigned above. The multiplicity of the signals is likely caused by the chain defects occurring during the polymerisation.

\section{C.3.1 Determination of -CFH-XA chain end}

The ultimate $\mathrm{CFH}$ group (linked to the xanthate moiety) displays a number of correlations with both a $\mathrm{CF}_{2}$ group and another $\mathrm{CFH}$ groups (around -120 and -210 ppm, respectively). Depending on how the ultimate TrFE unit was added to the polymer (via $\mathrm{HH}$ or $\mathrm{TH}$ additions), two different correlation systems were observed. The different -CFH-XA-terminated chains are detailed in Figure S25. For a better understanding, schematic representations of the two correlation systems are presented in Figure S26 (for the [TH]-XA, two splitting patterns are presented) and Figure S27 (for the [HH]-XA, only one splitting pattern is supplied).

First, the most intense correlations in the ${ }^{19} \mathrm{~F}$ COSY spectrum are assigned to the [TH]-XA (- $\left.\mathrm{CF}_{2}-\mathrm{CFH}-\mathrm{CF}_{2}-\mathrm{CFH}-\mathrm{XA}\right)$ chain end. Two different correlation systems were identified (Figure 6). In one system, the fluorine atom in the CFH resonance centered at -172.7 $\mathrm{ppm}$ couples with two isochronous fluorine atoms of a $\mathrm{CF}_{2}$ group yielding the resonance centered at $-118.6 \mathrm{ppm}$ ( $\mathrm{no}^{2} \mathrm{~J}_{\mathrm{F}-\mathrm{F}}$ coupling nor difference of chemical shift are observed for both these fluorine atoms).

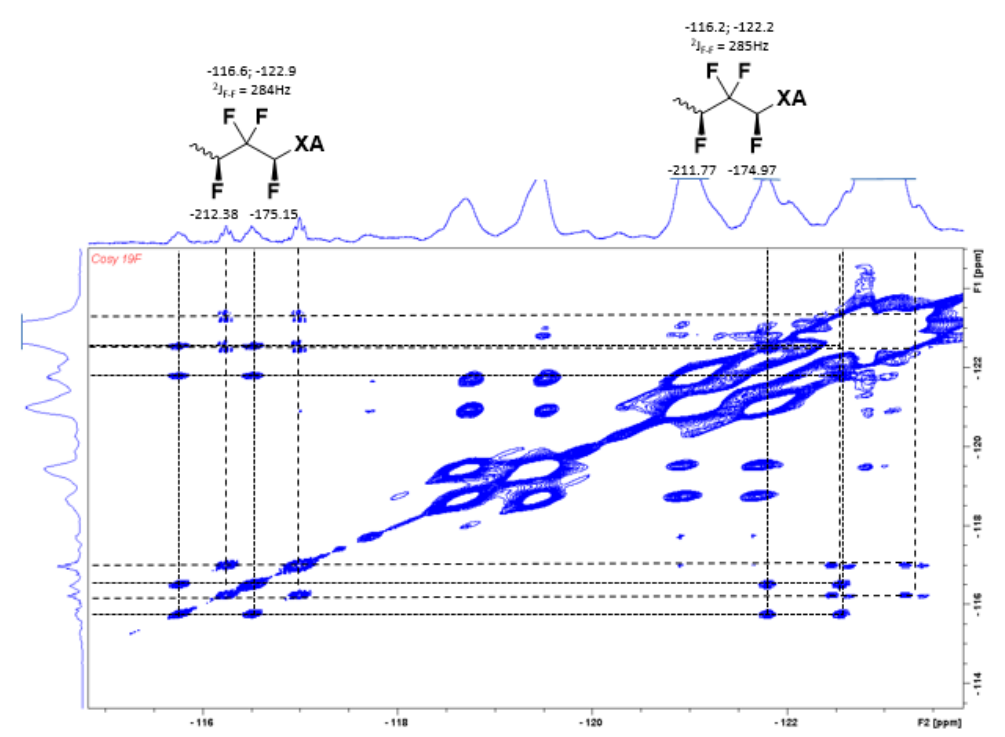

Figure 7. Zoom [-115.6 - -122.8ppm; $-113.8-123.4 \mathrm{ppm}]$ on the ${ }^{19} \mathrm{~F}$ COSY spectrum on the $\mathrm{CF}_{2} / \mathrm{CF}_{2}$ correlations zone for PTrFE made by RAFT (Entry 4, Table 1). 


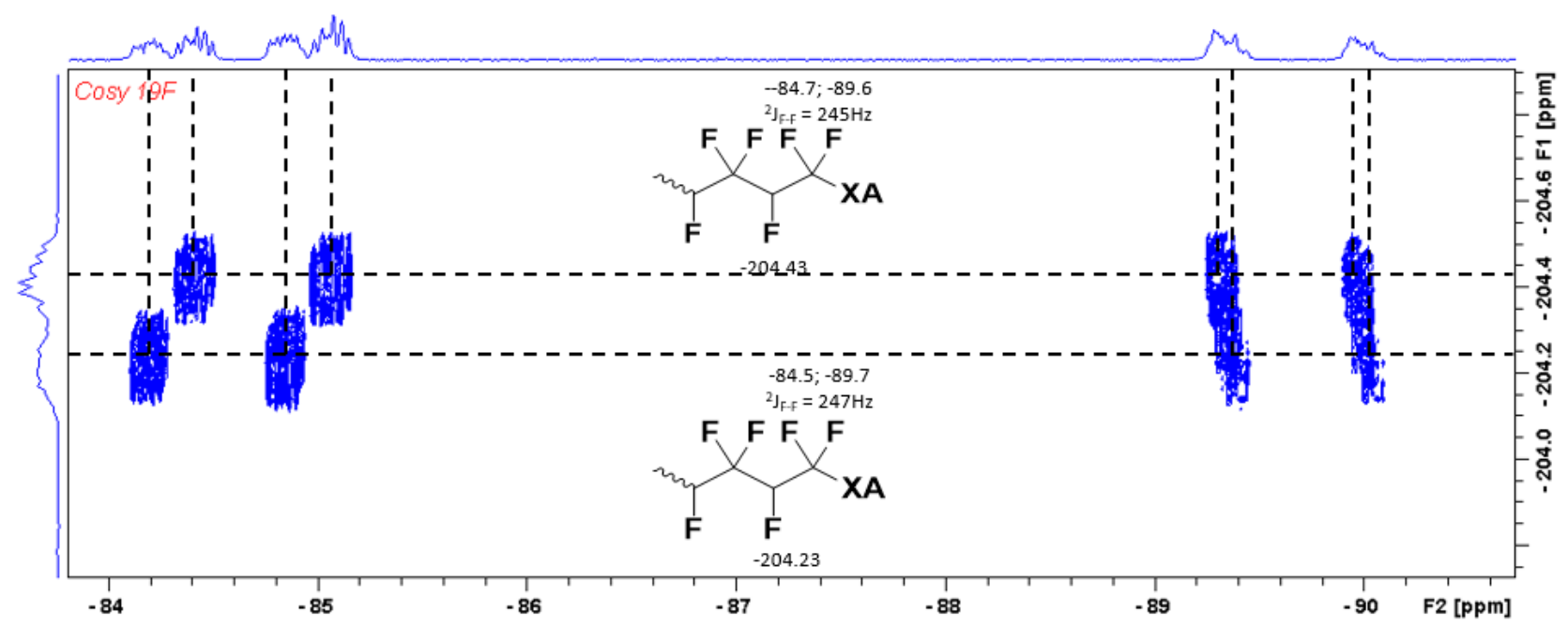

Figure 8. Zoom on the $[-84--90.6 \mathrm{ppm} ;-203.8-204.8 \mathrm{ppm}]$ region $\left(\mathrm{CF}_{2} / \mathrm{CFH}\right.$ correlations zone) of the ${ }^{19} \mathrm{~F}$ COSY spectrum of a PTrFE made by RAFT (Entry 4, Table 1$)$.

In addition, the fluorine atoms of this $\mathrm{CF}_{2}$ group are coupled with another fluorine atom of a CFH group resonating at $-212.2 \mathrm{ppm}$, confirming the expected [TH]-XA structure $\left(-\mathrm{CF}_{2}-\mathrm{CFH}-\mathrm{CF}_{2}-\mathrm{CFH}-\mathrm{XA}\right)$. The second [TH]-XA system is more complex (see schematic representation in Figure S26) with two sets of signals caused by the stereochemical configuration of the penultimate dyad. The fluorine atom (resonances at -175.15 and $-175.97 \mathrm{ppm}$ ) of the terminal CFH group is coupled ( ${ }^{3} \mathrm{FFF}_{\mathrm{FF}}$ ranging from 10 to $20 \mathrm{~Hz}$ ) with two nonequivalent fluorine atoms of the adjacent $\mathrm{CF}_{2}$ group with resonances at $-116.6,-122.9$, and -116.2 and $-122.2 \mathrm{ppm}$. This constitutes a meso dyad $\left({ }^{2} \mathrm{~J}_{\mathrm{FF}}=285 \mathrm{~Hz}\right)$. A gHSQC experiment confirmed that these nonequivalent fluorine atoms are connected to the same carbon atom (resonances at 114.35 and 114.48 ppm respectively, Figure S28). The ${ }^{19} \mathrm{~F}$ COSY spectrum does not show any other correlation than the ${ }^{2} \mathrm{~J}$ coupling in the $\mathrm{CF}_{2}-\mathrm{CF}_{2}$ correlation region (-115 to $-123 \mathrm{ppm}$ ) (Figure 7). However, a 3-bond correlation (at -211.77 and $-212.20 \mathrm{ppm}$ ) with the CFH of the penultimate TrFE unit was observed (Figure S29), confirming again the [TH]-XA expected structure. Interestingly, the ${ }^{4} \mathrm{~J}$ coupling between the ultimate and penultimate $\mathrm{CFH}$ group (Figure $\mathrm{S} 30$ ) could be observed on the $\operatorname{COSY}{ }^{19} \mathrm{~F}$ spectrum.
The less intense $[\mathrm{HH}]-\mathrm{XA}$ correlation system $\left(-\mathrm{CFH}_{-}-\mathrm{CF}_{2}-\mathrm{CF}_{2}-\mathrm{CFH}-\right.$ $\mathrm{XA}$ ) is assigned here. Depending on the configuration of the $\mathrm{CFH}$ groups, 4 different sets of signals have been observed and are summarised in Table 3 and in Figures S31 to S34. This type of chain end shows a typical correlation pattern in the ${ }^{19} \mathrm{~F}$ COSY spectrum, between the fluorine atom of a CFH group (resonance around - 175 $\mathrm{ppm}$ ) and two sets of two non-equivalent fluorine atoms belonging to the $\mathrm{CF}_{2}$ groups of the ultimate and penultimate TrFE units (Figures S31 to S34) resonating at around $-116,-120,-123$ and $-127 \mathrm{ppm}$. This typical system is represented schematically in Figure S27. Each [HH]XA chain end possesses the same splitting pattern, but with different chemical shifts due to the difference of stereochemical configuration of the CFH of the last three dyads.

As in the case of the [TH]-XA chain ends, each fluorine atom of this $\mathrm{CF}_{2}$ groups yields a doublet of doublets with a large ${ }^{2} \mathrm{~J}_{\mathrm{F}-\mathrm{F}}(\mathrm{ca} .282 \mathrm{~Hz}$ for the fluorine atoms at -116 and $-123 \mathrm{ppm}$ and around $287 \mathrm{~Hz}$ for the fluorine atoms at -120 and -127 ppm) and a smaller ${ }^{3} \mathrm{~J}_{\mathrm{F}-\mathrm{F}}$ coupling constant of about $15-20 \mathrm{~Hz}$ (although an accurate measurement of this coupling constant was not possible). The values of these ${ }^{2} \mathrm{JFF}_{\mathrm{FF}}$ coupling constants allow the identification of the fluorine atom resonance pairs at $(-116,-123)$ and $(-120,-126)$ ppm. This could not

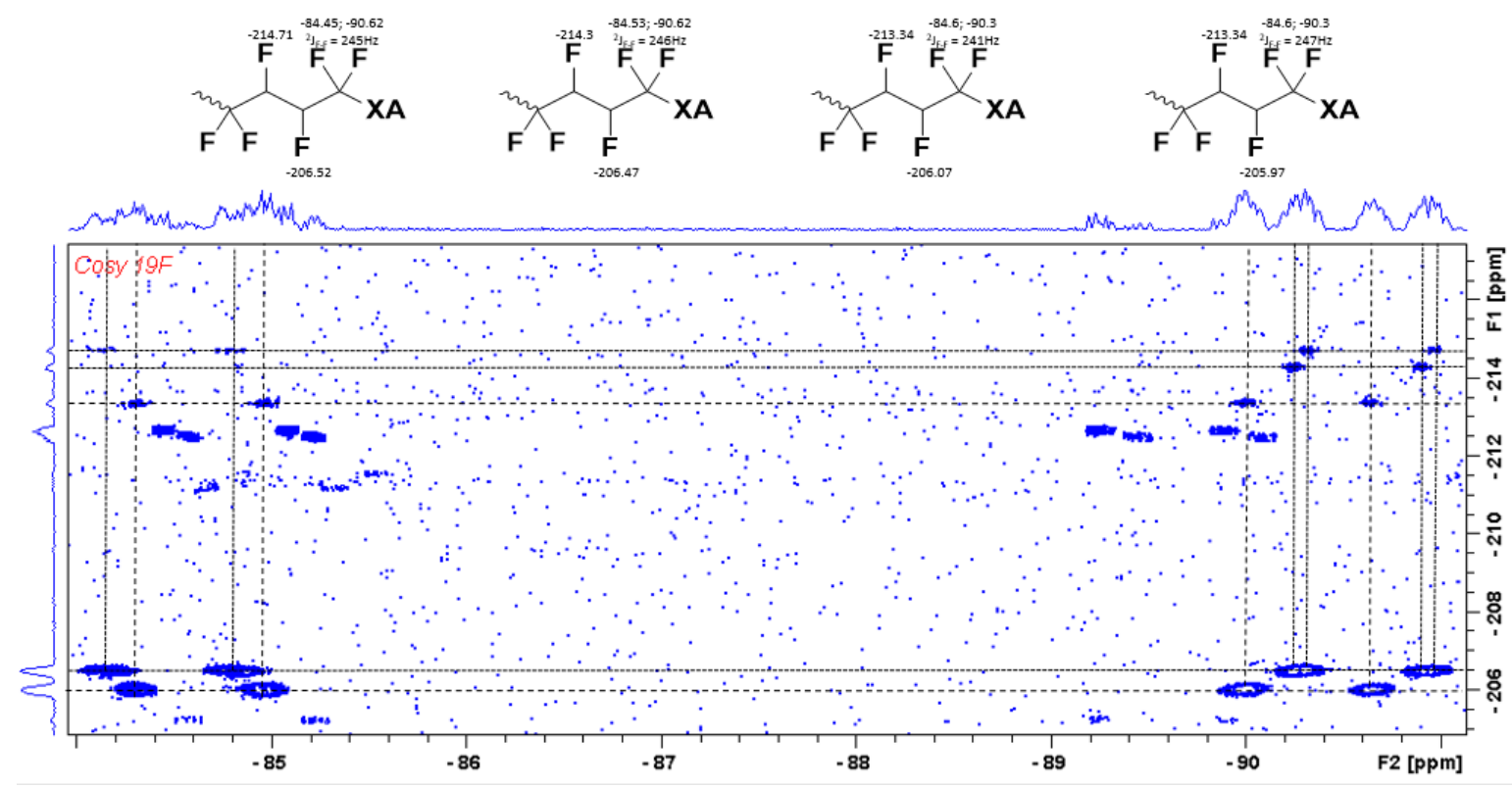

Figure 9. Zoom on the [-84 - -91ppm; $-205--217 \mathrm{ppm}]$ region ( $\mathrm{CF}_{2} / \mathrm{CFH}$ correlations zone) of the ${ }^{19} \mathrm{~F}$ COSY spectrum for PTrFE made by RAFT (Entry 4, Table 1$)$. 
Table 5. NMR signal assignments of the chain-ends of PtrFE made by RAFT polymerization.

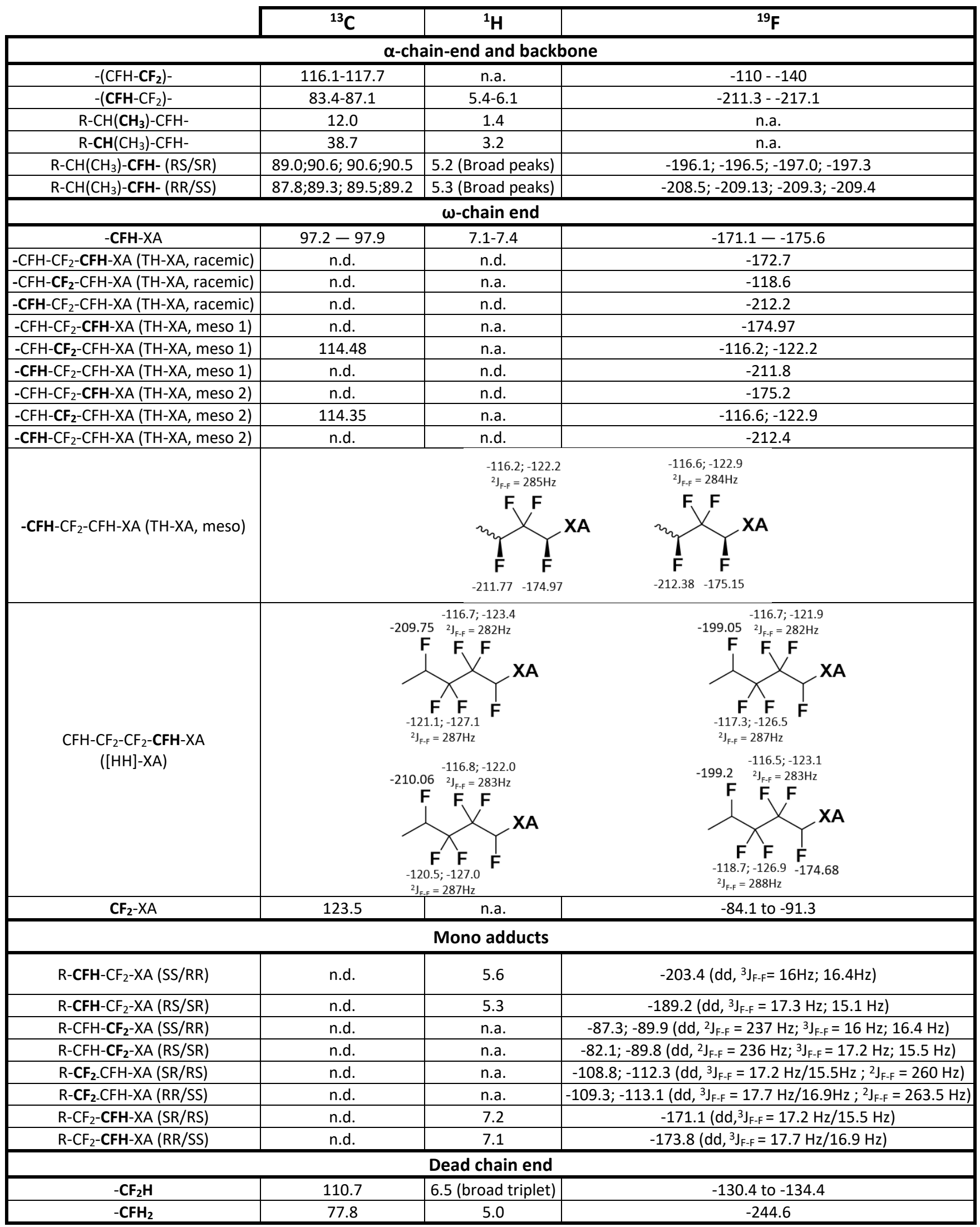

signals were too weak. All these $\mathrm{CF}_{2}$ fluorine atoms show correlation spots with each other, further confirming the $-\mathrm{CF}_{2}-\mathrm{CF}_{2}-\mathrm{CFH}-\mathrm{XA}$ sequence (Figure S35). The coupling with the fluorine atom of the CFH group (resonance at $-199 \mathrm{ppm}$ or $-210 \mathrm{ppm}$ depending of its stereochemical configuration) of the penultimate TrFE unit is also visible in the ${ }^{19} \mathrm{~F}$ COSY spectrum (Figure S36).

\section{C.3.2 Determination of $-\mathrm{CF}_{2}-\mathrm{XA}$ chain end}

The $\mathrm{CF}_{2}$-XA zone (from -84 to $-92 \mathrm{ppm}$ ) displays 10 different structures corresponding to the [HT]-XA and [TT]-XA chain ends. The most representative correlations on the ${ }^{19} \mathrm{~F}$ COSY spectrum are presented Figure 8 and Figure 9 . The other correlations are barely visible because they are too close to the background signal. The broad resonances visible in the ${ }^{19} \mathrm{~F}\left\{{ }^{1} \mathrm{H}\right\}$ spectrum centered at -84.2 
and $-91.5 \mathrm{ppm}$ stem from the overlap of the ultimate $\mathrm{CF}_{2}$ group signals. The non-equivalence of the fluorine atoms of this ultimate $\mathrm{CF}_{2}$ moiety results in the presence of two sets of split resonances, with a strong ${ }^{2} \mathrm{~J}_{\mathrm{F}-\mathrm{F}}$ coupling of about $245 \mathrm{~Hz}$. As in the previous cases of the CFH-XA chain ends, the lack of resolution does not allow an accurate determination of ${ }^{3} \mathrm{~J}_{\mathrm{F}-\mathrm{F}}$. Among the 10 correlation systems observed, four $\mathrm{CF}_{2}$ groups are coupled with only one $\mathrm{CFH}$ and are thus assigned to the regular HT structure $\left(-\mathrm{CFH}_{-}-\mathrm{CF}_{2}-\mathrm{CFH}-\mathrm{CF}_{2}-\mathrm{XA}\right.$, Figure 8). The structures where the ultimate $\mathrm{CF}_{2}$ group is coupled with two $\mathrm{CFH}$ groups were attributed to the [TT]-XA structure $\left(-\mathrm{CF}_{2^{-}}\right.$ $\mathrm{CFH}-\mathrm{CFH}-\mathrm{CF}_{2}-\mathrm{XA}$, Figure 9). The ${ }^{19} \mathrm{~F}$ COSY spectrum does not allow the accurate assignment of the $\mathrm{CF}_{2}$ group of the penultimate TrFE unit due to the important number of weak signals in the same area of the spectrum. This complexity arises from the large number of structures and complex splitting patterns resulting from the CFH stereocenters and the various chain defects possibly present close to the penultimate TrFE unit. Indeed, the chemical shifts will be slightly different for a [HT]-XA (or [TT]-XA) chain end if an HHTT addition (or $\mathrm{HH}$ addition) occurred a couple of TrFE units before, making the complete and accurate assignment of the $-\mathrm{CF}_{2}-\mathrm{XA}$ chain end impossible.

Table 4 summarises the chemical shifts and assignments of the ${ }^{1} \mathrm{H}$ and ${ }^{19} \mathrm{~F}$ NMR signals of these PTrFE $\omega$-chain end. Table 5 summarises the chemical shifts and assignments of the ${ }^{1} \mathrm{H}$ and ${ }^{19} \mathrm{~F}$ NMR signals of both the $\alpha$ - and $\omega$-chain end of PTrFE made by RAFT polymerisation.

\section{Conclusion}

Using a large array of NMR experiments combining the three polymer nuclei $\left({ }^{1} \mathrm{H},{ }^{13} \mathrm{C}\right.$ and $\left.{ }^{19} \mathrm{~F}\right)$, the chain-end microstructures of a PTrFE made by RAFT have been fully described. The study of the $\alpha$ chain-end and of the monoadducts formed at the very beginning of the polymerisation showed that, unexpectedly, the initiation occurs preferentially on the head ( $\mathrm{CF}_{2}$ group) of the monomer rather than its tail (CFH group). This oddity has been rationalized by DFT calculations as resulting from an $\mathrm{H}$-bond stabilization of the transition state and product of the head-end addition. The study of the $\omega$-chain end allowed the unequivocal identification of the various termini formed by irreversible transfers $\left(-\mathrm{CF}_{2} \mathrm{H}\right.$, and $\left.\mathrm{CFH}_{2}\right)$ or by reversible transfer to the RAFT chain transfer agent $\left(\mathrm{CF}_{2}-\mathrm{XA}\right.$, and $\mathrm{CFH}-$ $X A$, where $X A$ is a O-ethyl xanthate group). This work allows a better understanding of the RAFT polymerisation of TrFE and paves the way to the study of the RAFT copolymerisation of VDF and TrFE.

\section{Author Contributions}

Vincent BOUAD: Conceptualization, Methodology, validation, Investigation, Writing Original Draft, Review \& Editing. Marc GUERRE: Conceptualization, Methodology. Cedric TOTEE: Methodology. Gilles SILLY: Methodology. Bruno AMEDURI: Writing Review \& Editing. Rinaldo POLI : Methodology, Software, Formal analysis, Writing - Review \& Editing. Vincent LADMIRAL: Conceptualization, Methodology, Writing Original draft, Review \& Editing, Supervision, Funding acquisition.

\section{Conflicts of interest}

There are no conflicts to declare.

\section{Acknowledgements}

This work was partly supported by the the French National Research Agency (NanoPiC grant, ANR-16-CE08-0025). The authors thank Arkema (Pierre-Bénite, France) for providing TrFE.

\section{References}

1 John Scheirs, Polym. Int., 1999, 426, 8103.

2 B. Boutevin and B. Ameduri, Well-Architectured Fluoropolymers: Synthesis, Properties, and Applications, Elsevier, Oxford, 2004.

3 G. J. Puts, P. Crouse and B. M. Ameduri, Chem. Rev., 2019, 119, 1763-1805.

4 T. Yamada, Jpn. J. Appl. Phys., 1981, 20, 121-124.

5 Y. Oka, N. Koizumi and Y. Murata, J. Polym. Sci. Part B Polym. Phys., 1986, 24, 2059-2072.

6 Y. Oka and N. Koizumi, Jpn. J. Appl. Phys., 1984, 23, 748753.

7 R. E. Naylor and S. W. Lasoski, J. Polym. Sci., 1960, 44, 1-7.

8 C. W. Wilson and E. R. Santee, J. Polym. Sci. Part C Polym. Symp., 2007, 8, 97-112.

9 T. Yagi, Polym. J., 1979, 11, 353-358.

10 E. B. Twum, C. Gao, X. Li, E. F. McCord, P. A. Fox, D. F. Lyons and P. L. Rinaldi, Macromolecules, 2012, 45, 5501-5512.

11 A. E. Tonelli, F. C. Schilling and R. E. Cais, Macromolecules, 1981, 14, 560-564.

F. A. Bovey, R. E. Cais, L. W. Jelinski, F. C. Schilling, W. H. Starnes and A. E. Tonelli, in Polymer Characterization Advances in Chemistry Series, C.D. Craver, ACS, Washington D.C., 1983, 421-439.

A. E. Tonelli, F. C. Schilling and R. E. Cais, in Advances in Chemistry Series, 1983, pp. 441-454.

14 S. A. Reinsberg, S. Ando and R. K. Harris, Polymer, 2000, 41, 3729-3736.

15 WO 2015/173193 A1, 2015.

16 M. Guerre, B. Campagne, O. Gimello, K. Parra, B. Ameduri and V. Ladmiral, Macromolecules, 2015, 48, 7810-7822.

17 M. Guerre, G. Lopez, T. Soulestin, C. Totée, B. Améduri, G. Silly and V. Ladmiral, Macromol. Chem. Phys., 2016, 217, 2275-2285.

M. Guerre, S. M. W. Rahaman, B. Améduri, R. Poli and V. Ladmiral, Macromolecules, 2016, 49, 5386-5396.

X. Liu, O. Coutelier, S. Harrisson, T. Tassaing, J. D. Marty and M. Destarac, ACS Macro Lett., 2015, 4, 89-93. X. Li, E. F. McCord, S. Baiagern, P. Fox, J. L. Howell, S. K. Sahoo and P. L. Rinaldi, Magn. Reson. Chem., 2011, 49, 413-424.

A. E. Tonelli, F. C. Schilling and R. E. Cais, Macromolecules, 1982, 15, 849-853.

22 V. Bouad, M. Guerre, C. Totée, G. Silly, O. Gimello, B. Améduri, J.-F. Tahon, R. Poli, S. Barrau and V. Ladmiral, Submitted.

E. Girard, J. D. Marty, B. Ameduri and M. Destarac, ACS Macro Lett., 2012, 1, 270-274. T. Soulestin, P. Marcelino Dos Santos Filho, V. Ladmiral, C. Totée, G. Silly, T. Lannuzel, F. Domingues Dos Santos and B. Ameduri, Macromolecules, 2017, 50, 503-514.

W. R. Dolbier, Guide to Fluorine NMR for Organic Chemists, Wiley, Hoboken, $1^{\text {st }}$ Edition, 2009. W. R. Dolbier, Chem. Rev., 1996, 96, 1557-1584. 